\section{Influence of Surface Treatments and Adhesive Systems on Lithium Disilicate Microshear Bond Strength}

Celso Sebastião Garboza', Sandrine Bittencourt Berger ${ }^{1}$, Ricardo Danil Guiraldo ${ }^{1}$, Ana Paula Piovezan Fugolin ${ }^{2}$, Alcides Gonini-Júnior ${ }^{1}$, Sandra Kiss Moura', Murilo Baena Lopes ${ }^{1}$

\begin{abstract}
'Department of Restorative Dentistry, School of Dentistry, UNOPAR - Universidade Norte do Paraná, Londrina, PR, Brazil ${ }^{2}$ Department of Restorative Dentistry, Piracicaba Dental School, UNICAMP - Universidade Estadual de Campinas, Piracicaba, SP, Brazil
\end{abstract}

Correspondence: Ricardo Danil Guiraldo, Rua Marselha 183, 86041-140 Londrina, PR, Brasil. Tel: +55-43-3371-7700. e-mail: rdguiraldo@gmail.com

\begin{abstract}
The purpose of this study was to evaluate the microshear bond strength of ceramic prosthetic structures reinforced by lithium disilicate cemented with resin cement under conditions of different surface treatments and adhesive systems. Seventy-two rectangular blocks of lithium disilicate $(6.5 \mathrm{~mm}$ long $\times 5 \mathrm{~mm}$ wide $\times 1 \mathrm{~mm}$ thick) were fabricated, air abraded with $50-\mu \mathrm{m} \mathrm{Al}_{2} \mathrm{O}_{3}$ particles and divided into six groups $(n=12)$ depending on the surface pretreatments. The groups were as follows: $10 \mathrm{HF} / \mathrm{S} / \mathrm{SBM}: 10 \%$ hydrofluoric acid etched for $20 \mathrm{~s}(10 \mathrm{HF})+$ silane (S) + Adper Scotchbond Multi-Purpose (SBM); $10 \mathrm{HF} / \mathrm{S} / \mathrm{SB}: 10 \mathrm{HF}+\mathrm{S}+$ Single Bond Universal (SB); 10HF/SBM; $10 \mathrm{HF} / \mathrm{SB} ; \mathrm{S} / \mathrm{SBM}$ and S/SB. Two 1-mm-long plastic tubes were placed on the specimens, filled with RelyX $A R C$ resin cement and cured for $20 \mathrm{~s}$ per tube. The plastic tube was removed, and the microshear bond strength was tested. Data were submitted to analysis of variance and Tukey's tests $(\alpha=0.05)$. Fractured specimens were observed under optical microscopy. For both adhesives, the bond strengths (MPa) of groups treated with acid-etching and silane $(10 \mathrm{HF} / \mathrm{S} / \mathrm{SB}: 24.82,10 \mathrm{HF} / \mathrm{S} / \mathrm{SBM}: 24.90)$ were higher $(\mathrm{p}<0.001)$ than those of groups treated with acid-etching (10HF/SB: 16.47, 10HF/SBM: 19.94) only or only silane (S/SB: 18.42 , S/SBM: 13.24). All groups showed a predominance of failure adhesive. The silanization should be a clinical step in cementing ceramic structures reinforced by lithium disilicate, even with the application of universal adhesive that contains silane in its formulation.
\end{abstract}

Key Words: microshear bond strength, lithium disilicate, surface treatments, adhesive systems.

\section{Introduction}

In recent years, the use of indirect metal-free ceramic restorations has grown considerably due to the increased demand for esthetic restorative procedures in Dentistry (1). Lithium disilicate is a dental ceramic that mimics the esthetics and strength of the natural tooth structure (2). The $70 \%$ crystal phase of this unique glass-ceramic material refracts light naturally and provides superior structural reinforcement, imparting a greater flexural strength than the one associated with traditional feldspathic porcelain or leucite-reinforced glass ceramics $(2,3)$. Lithium disilicate ceramic is being increasingly used to replace zirconia $(4,5)$. The fatigue behavior and reliability of lithium disilicate and zirconia all-ceramic crowns were recently described $(5,6)$. The results showed that lithium disilicate ceramic crowns in a monolithic/ful anatomical configuration are fatigue-resistant, whereas zirconia crowns are highly susceptible to mouth-motion cyclic loading with early veneer failures $(5,6)$.

The clinical success of ceramic restorations depends on several factors, like the cementation procedure and composition of the ceramic material (7). Different ceramic surface treatments have been introduced to improve resin bonding to ceramic (7). A lithium disilicate glass ceramic
(IPS e.max Press; Ivoclar Vivadent, Schaan, Liechtenstein) may be adhesively cemented, but retention may be inadequate when the retentive area is small (7). Resin cement bonding to the tooth is aided by acid etching of enamel or dentin and by a dentin adhesive (8). Techniques for bonding to ceramic IPS e.max Press take advantage of the formation of chemical bonds and micromechanical interlocking at the resin-ceramic surface (7).

Etching with hydrofluoric acid (HF) is recommended before bonding lithium disilicate crowns (8). Etching with $\mathrm{HF}$ creates a rough surface on the bonding area of the ceramic material, which enhances bonding between the ceramic and resin cement. HF removes the glass matrix and the second crystal phase, creating irregularities within the lithium disilicate crystals of IPS e.max Press for bonding $(7,9)$. Another recommended treatment for ceramic surfaces involves airborne abrasion with 50$\mu \mathrm{m}$ aluminum oxide $\left(\mathrm{Al}_{2} \mathrm{O}_{3}\right)$ particles to aid mechanical retention (7). Air particle abrasion is a standard procedure performed by the dental laboratory before delivery of the ceramic piece to the dentist for cementing. After air abrasion, the ceramic surface must be coated with a suitable silane, which forms chemical bonds between the inorganic phase of the ceramic and the organic phase of 
the resin cement $(7,9)$.

The introduction of universal adhesives presents a new simplified approach for bonding ceramic to resin cements. Universal adhesives contain silane and a monomer called 10-methacryloxydecyl dihydrogen phosphate (MDP), which helps bonding the ceramic to the resin in a cement (2). However, the effectiveness of universal adhesives with lithium disilicate has not been thoroughly investigated (2). The aim of this study was to evaluate the microshear bond strength of ceramic prosthetic structures reinforced by lithium disilicate cemented with resin cement under conditions of different surface treatments and adhesive systems. The null hypotheses tested were that 1) different surface treatments and 2) different adhesive systems do not affect the microshear bond strength of ceramic structures reinforced by lithium disilicate.

\section{Material and Methods}

\section{Materials and Specimen Preparation}

Adhesives used for specimen preparation are described in Table 1. Seventy-two rectangular blocks $(6.5-\mathrm{mm}$ long $\times 5-\mathrm{mm}$ wide $\times 1-\mathrm{mm}$ thick) of IPS e.max Press ceramic (Ivoclar Vivadent), shade LT D3, were fabricated in accordance with the manufacturer's instructions. Rectangular wax patterns were fabricated, subjected to spruing and attached to a muffle (four per muffle) base with a surrounding paper cylinder. Wax patterns were invested with phosphate-based material (IPS PressVest Speed, Ivoclar Vivadent). Wax was eliminated in an automatic furnace (Vulcan A-550; Degussa-Ney, Yucaipa, CA, USA) at $850^{\circ} \mathrm{C}$ for $1 \mathrm{~h}$. Eighteen IPS e.max Press ceramic ingots $(3 \mathrm{~g}$ ) were pressed into the molds (four per mold) in an automatic press furnace (EP 600; Ivoclar Vivadent). After cooling, specimens were divested with glass sphere (Rolloblast; Renfert GmbH, Hilzingen, Germany) and submitted to manually (oscillatory movements) wet polishing with 600- and 1200-grit silicon carbide abrasive papers (Norton SA, São Paulo, SP, Brazil) to obtain a flat

Table 1. Adhesive systems evaluated in the study and composition according to their manufacturers

\begin{tabular}{cc}
\hline Adhesive & Composition \\
\hline $\begin{array}{c}\text { Adper Scotchbond Multi-Purpose } \\
\text { (3M ESPE, St Paul, MN, USA) }\end{array}$ & Bis-GMA, HEMA \\
& Bis-GMA, MDP, \\
dimethacrylate resins, \\
HEMA, Vitrebond \\
(3M ESPE, St Paul, MN, USA) & copolymer, silane, \\
& ethanol, water \\
\hline
\end{tabular}

HEMA: 2-hydroxyethyl methacrylate; Bis-GMA: 2,2-bis[4-(2hydroxy-3-methacryloyloxypropyl)phenyl]-propane; MDP: 10methacryloyloxydecyl dihydrogen phosphate. surface ( 2 min per carbide abrasive paper by the same operator). Specimens were air abraded with $50-\mu \mathrm{m} \mathrm{Al}_{2} \mathrm{O}_{3}$ particles (Bioart, São Carlos, SP, Brazil) for $5 \mathrm{~s}$ under 2 bar with a sandblasting device (Microetch, Bioart) at a 10 $\mathrm{mm}$ distance and perpendicular to the ceramic surface. All specimens were cleaned by ultrasound in distilled water for $20 \mathrm{~s}$.

Specimens were divided into 6 groups $(n=12)$ depending on the surface pretreatments, as follows: 10HF/S/SBM: $10 \%$ hydrofluoric acid etched for $20 \mathrm{~s}$ $(10 \mathrm{HF})+$ silane $(\mathrm{S})+$ Adper Scotchbond Multi-Purpose (SBM); $10 \mathrm{HF} / \mathrm{S} / \mathrm{SB}: 10 \mathrm{HF}+\mathrm{S}+$ Single Bond Universal (SB); $10 \mathrm{HF} / \mathrm{SBM} ; 10 \mathrm{HF} / \mathrm{SB} ; \mathrm{S} / \mathrm{SBM}$; and S/SB. The test surfaces of groups $10 \mathrm{HF} / \mathrm{S} / \mathrm{SBM}, 10 \mathrm{HF} / \mathrm{S} / \mathrm{SB}, 10 \mathrm{HF} / \mathrm{SBM}$ and $10 \mathrm{HF} /$ SB were etched with 10\% HF (Dentsply, Petrópolis, RJ, Brazil) for $20 \mathrm{~s}$, followed by rinsing with distilled water for $1 \mathrm{~min}$. Specimens were rinsed, ultrasonically cleaned in distilled water for $20 \mathrm{~min}$ and dried by compressed air. One layer of a silane coupling agent (RelyX Ceramic Primer, 3M ESPE) was applied to all ceramic specimens of groups $10 \mathrm{HF} / \mathrm{S} / \mathrm{SBM}$ (after the HF etching step), 10HF/S/SB (after the HF etching step), S/SBM and S/SB by a microbrush, followed by air drying for $10 \mathrm{~s}$ with room-temperature air. Adper Scotchbond Multi-Purpose (groups 10HF/S/ SBM, 10HF/SBM and S/SBM) or Single Bond Universal (groups $10 \mathrm{HF} / \mathrm{S} / \mathrm{SB}, 10 \mathrm{HF} / \mathrm{SB}$ and $\mathrm{S} / \mathrm{SB}$ ) was applied to all pretreated ceramic surfaces for $20 \mathrm{~s}$ by a microbrush, followed by air thinning for $10 \mathrm{~s}$. Adhesives were cured for $10 \mathrm{~s}$ with a LED curing light $\left(1400 \mathrm{~mW} / \mathrm{cm}^{2}\right.$; Radii-Cal, SDI, Bayswater, VIC, Australia). Uniformity of the curing light output was controlled with a power meter (Ophir Optronics Inc., Danvers, MA, USA) after finishing every batch of 12 specimens.

Two 1-mm-long transparent plastic tubes (Tygon Tubing, TYG-03; Saint-Gobain Performance Plastic, Miami Lakes, FL, USA) with a $0.75 \mathrm{~mm}$ internal diameter were placed on the rectangular blocks of lithium disilicate and filled with RelyX ARC resin cement (shade A3; 3M ESPE), according to the methodology suggested by another study (10). Composite-filled tubes were fixed to the surface of each ceramic specimen and light cured (Radii-Cal, SDI) for $20 \mathrm{~s}$ per tube.

\section{Testing Procedures}

Before microshear bond strength testing, the plastic tube was removed revealing a cylinder of composite and exposing two cement cylinders with a union area of 0.38 $\mathrm{mm}^{2}$ each. Specimens were mounted onto a steel device in a universal testing machine (DL2000; Emic, São José dos Pinhais, PR, Brazil). Load was applied at the base of the cylinder by a steel wire $(0.2 \mathrm{~mm}$ diameter $)$ at a speed of $0.5 \mathrm{~mm} / \mathrm{min}$ until frcture of the microshear bond 
strength. Bond strength values were calculated and the data were expressed in MPa. Each group contained 12 blocks and each block provided two cylinders, a total of 24 cylinders per group.

\section{Statistical Analysis}

Statistical analysis was performed with the Minitab 16 program for Windows 8 (Minitab, State College, PA, USA). Normality of the distributions was tested by the Kolmogorov-Smirnov normality test. Subsequently, parametric tests were used. Data for the microshear bond strength values were statistically evaluated by two-way analysis of variance (ANOVA). Tukey's test was used to analyze the differences in bond strength values according to the variables "surface treatment" and "adhesive system" $(\alpha=0.05)$.

\section{Failure Analysis}

Fractured specimens were observed qualitatively under optical microscopy (Olympus Corp, Tokyo, Japan) at $40 \times$ magnification. The failure modes were classified as follows: adhesive (ceramic-resin cement interface), cohesive (in the resin cement) and mixed (involving $\approx$ adhesive and cohesive failures). The specimen surfaces were gold coated with a sputter coater (Balzers-SCD 050, Balzers Union AG, Balzers, Liechtenstein) for $180 \mathrm{~s}$ at 40 $\mathrm{mA}$. The specimens were then mounted on coded brass stubs and examined by scanning electron microscopy

Table 2. Microshear bond strength means (MPa) for all groups

\begin{tabular}{lccc}
\hline \multirow{2}{*}{$\begin{array}{l}\text { Adhesive } \\
\text { system }\end{array}$} & \multicolumn{3}{c}{ Surface treatment } \\
\cline { 2 - 4 } & $10 \mathrm{HF}+\mathrm{S}$ & $10 \mathrm{HF}$ & $\mathrm{S}$ \\
\hline SBM & $24.90(3.15) \mathrm{A}, \mathrm{a}$ & $19.94(1.20) \mathrm{A}, \mathrm{b}$ & $13.24(0.62) \mathrm{B}, \mathrm{c}$ \\
$\mathrm{SB}$ & $24.82(2.43) \mathrm{A}, \mathrm{a}$ & $16.47(0.61) \mathrm{B}, \mathrm{b}$ & $18.42(1.22) \mathrm{A}, \mathrm{b}$ \\
\hline
\end{tabular}

SBMP: Adper Scotchbond Multi-Purpose. SB: Single Bond Universal. Mean values followed by different uppercase letters in columns and lowercase letters in rows are significantly different at $p<0.001$ (Tukey test). Standard deviations are in parentheses. 10HF: 10\%hydrofluoric acid for $20 \mathrm{~s}$; S: silane.
(SEM; LEO 435 VP, Cambridge, UK), operated at 20 kV, by a single operator.

\section{Results}

Mean values of the microshear bond strengths are in Table 2. The bond strength was higher in groups with $\mathrm{HF}$ $+\mathrm{S}(10 \mathrm{HF} / \mathrm{S} / \mathrm{SBM}$ and $10 \mathrm{HF} / \mathrm{S} / \mathrm{SB})$ compared with groups with $\mathrm{HF}$ alone (10HF/SBM and 10HF/SB) or silane alone (S/ SBM and $S / S B)$, for both adhesive treatments $(p<0.001)$. For groups $10 \mathrm{HF} / \mathrm{S} / \mathrm{SBM}$ and $10 \mathrm{HF} / \mathrm{S} / \mathrm{SB}$, there was no statistically significant difference between the adhesives $(\mathrm{p}<0.001)$.

All groups showed a prevalence of adhesive failuresfor the different surface treatments and adhesive systems (Table 3). Figure 1 is a composite image of representative SEM micrographs of failure modes.

\section{Discussion}

The standard protocol for creating adhesive ceramic restorations reinforced by lithium disilicate requires blasting with $\mathrm{Al}_{2} \mathrm{O}_{3}$ (in the present study this treatment was performed in all groups, because for the ceramic restorations reinforced by lithium disilicate it is usually performed in the dental lab), conditioning and silanizing

Table 3. Failure mode (\%) for the different surface treatments and adhesive systems

\begin{tabular}{lccc}
\hline Group & $\begin{array}{c}\text { Adhesive } \\
\text { failures }\end{array}$ & $\begin{array}{c}\text { Cohesive } \\
\text { failures }\end{array}$ & $\begin{array}{c}\text { Mixed } \\
\text { failures }\end{array}$ \\
\hline 10HF/S/SBM & 87.4 & 4.1 & 8.4 \\
$10 \mathrm{HF} / \mathrm{S} / \mathrm{SB}$ & 75.0 & 16.6 & 8.4 \\
$10 \mathrm{HF} / \mathrm{SBM}$ & 91.6 & 4.2 & 4.2 \\
$10 \mathrm{HF} / \mathrm{SB}$ & 91.6 & 0.0 & 8.4 \\
$\mathrm{~S} / \mathrm{SBM}$ & 87.4 & 8.4 & 4.2 \\
S/SB & 100 & 0 & 0 \\
\hline
\end{tabular}

The failure mode was classified as follows: adhesive (ceramic-resin cement interface), cohesive (resin cement) and mixed (involving adhesive and cohesive failures).
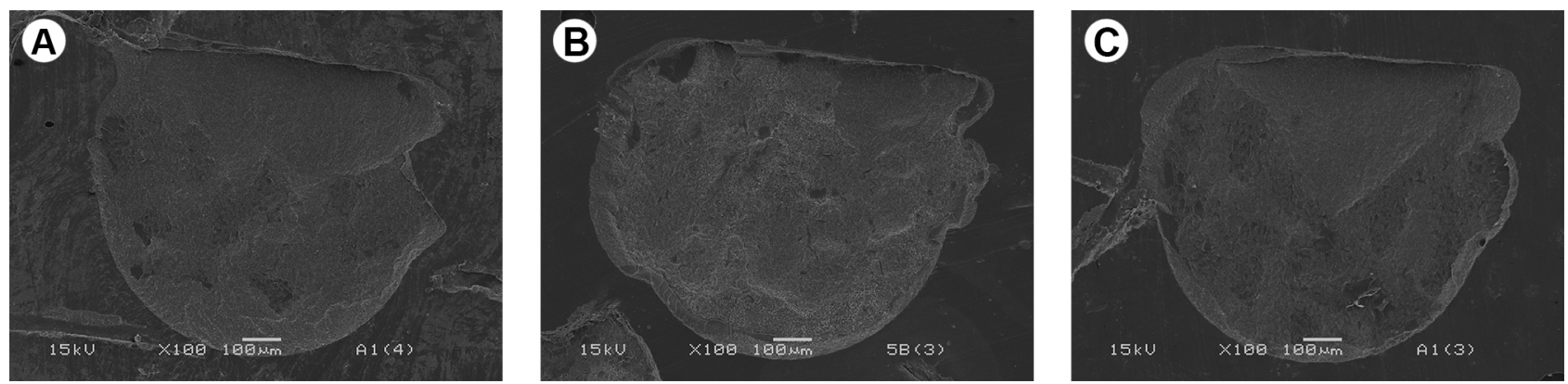

Figure 1. Composite image of representative SEM micrographs of failure modes: A: adhesive failure, B: cohesive failure and C: mixed failure. 
the ceramic surface. Adhesive must penetrate the resulting microretentions and bond chemically with the surface. Amaral et al. (11) demonstrated the ability of a universal adhesive to bond zirconia to resin. Another study by Kalavacharla et al. (2) found that the use of silane with a universal adhesive significantly increased the bond strength values between the lithium disilicate dental ceramic the resin composite. However, that study (2) did not compare the results of the universal adhesive to those of other adhesives without silane or MDP in their compositions and did not use resin cement. In the present study, where it was bonded with resin cement, there was no significant difference between the $\mathrm{HF}+\mathrm{S}$ groups using the SB adhesive (which contains MDP and silane) or the SBM adhesive (which does not have these components).

For the lithium disilicate-reinforced glass ceramic, the etching with hydrofluoric acid promoted higher values than the surface wear by 30- $\mu \mathrm{m}$-grit diamond bur and sandblasting with silica-coated aluminum oxide (12). In the current study, etching with hydrofluoric acid (group $10 \mathrm{HF} / \mathrm{SBM})$ produced higher bond strength values than silane (group S/SBM) with SBM adhesive, which is in agreement with Colares et al. (13) and Neis et al. (14). In this study, the SBM adhesive presented higher mean shear strength values than the SB adhesive (groups 10HF/ $\mathrm{SBM}$ and $10 \mathrm{HF} / \mathrm{SB}$ ). This result was not expected because $\mathrm{SB}$ contains monomeric MDP, which bonds chemically to nonprecious metals and tooth substrates $(15,16)$. MDP has an amphiphilic structure, with the vinyl and phosphate groups as the hydrophobic and hydrophilic moieties, respectively (17). The vinyl group may copolymerize with the resin monomer of the resin-based materials applied later (7). However, the hydrophilic part of the adhesive might affect negatively the bond strength compared with SBM. Moreover, SB contains silane in addition to MDP. Silane may increase the hydrophilicity of the adhesive, thereby predisposing the adhesive layer to hydrolytic degradation (17). These assumptions require further investigation.

Silanes are adhesion promoters that contain two different functional groups that may react and couple with various inorganic and organic materials (18). They are used to increase the bond of dissimilar materials. Hydrolysable functional groups react to the surface hydroxyl groups of inorganic substrates creating a siloxane bond (Si-O-Si) (18). The organic non-hydrolysable functional group with a C-C double bond can polymerize with resin composite monomers containing double bonds (18-20). It may be assumed that there should be equilibrium between the amount of the exposed hydroxyl groups of inorganic substrates and the hydrolysable functional groups in the silane (15). Thus, the quality of the formed siloxane bond is determined by the concentration of the silane solution (19) and the surface pretreatment protocol (which determines the number of exposed hydroxyl groups ) (20). This fact may explain the observed difference between groups S/SBM and S/SB.

A limitation of this study is that the resin cement was light-cured directly, without light transmission through ceramic. Inlays, onlays, laminate veneers and all-ceramic crowns are commonly luted with dual-cured resin cements because light transmission through the indirect restoration is reduced, so that the chemical reaction should theoretically guarantee a satisfactory degree of conversion (21). The light transmission spectrum through ceramic is influenced by its thickness, shade and opacity $(21,22)$. Using longer light-curing times results in a greater depth of resin composite polymerization, higher degree of conversion, greater hardness (22) and consequently improved mechanical and esthetic properties (21). According to Tanoue et al. (23), the same reasoning may be applied to light-cured resin cements. Thus, the present study evaluated the microshear bond strength of ceramic prosthetic structures reinforced by lithium disilicate with better mechanical properties of the resin cement.

In this study, the failure mode was not directly related to the microshear bond strength (Table 3). Although Groups 10HF/S/SBM and 10HF/S/SB showed higher bond strengths than the other groups, adhesive failure mode predominated in all groups. This result was also observed in a previous study, but using the microtensile test (7). Thus, based on the results of this study, the null hypotheses were rejected because different bond strength values of ceramic structures reinforced by lithium disilicate were found with different surface treatments and different adhesive systems. Within the limitations of the present study, the following conclusions can be drawn: 1) Etching with hydrofluoric acid and applying silane is a good surface treatment for cementing ceramic structures reinforced by lithium disilicate with either adhesive; 2) Silanization should be a clinical step in cementing ceramic structures reinforced by lithium disilicate, even with the application of universal adhesive that contains silane in its formulation.

\section{Resumo}

0 objetivo neste estudo foi avaliar a resistência de união ao microcisalhamento de estruturas protéticas cerâmicas reforçadas por dissilicato de lítio cimentadas com cimento resinoso sob diferentes tratamentos de superfície e sistemas adesivos. Setenta e duas barras retangulares de dissilicato de lítio $(6,5 \mathrm{~mm}$ de comprimento $\times 5 \mathrm{~mm}$ de largura $\times 1 \mathrm{~mm}$ de espessura) foram fabricadas, tratados com particulas de $\mathrm{Al}_{2} \mathrm{O}_{3}(50 \mu \mathrm{m})$ e dividido em seis grupos $(n=12)$ dependendo dos pré-tratamentos de superfície. Os grupos foram como se segue: 10HF/S/ SBM: condicionamento com ácido fluorídrico 10\% durante $20 \mathrm{~s}$ (10HF) + silano (S) + Adper Scotchbond Multi-Purpose (SBM); 10HF/S/SB: 
$10 \mathrm{HF}+\mathrm{S}+$ Single Bond Universal (SB); $10 \mathrm{HF} / \mathrm{SBM} ; 10 \mathrm{HF} / \mathrm{SB} ; \mathrm{S} / \mathrm{SBM}$; e $\mathrm{S} / \mathrm{SB}$. Dois tubos plásticos cilíndricos de $1 \mathrm{~mm}$ de comprimento foram colocados sobre os espécimes, preenchidos com cimento RelyX ARC e fotoativado durante $20 \mathrm{~s}$ por tubo. Os tubos plásticos foram removidos e a resistência de união ao microcisalhamento foi testada. Os dados foram submetidos à análise de variância e ao teste de Tukey $(\alpha=0,05)$. Espécimes fraturados foram observados sob microscopia óptica. Para ambos os adesivos, a resistência de união ( $\mathrm{MPa}$ ) dos grupos tratados com condicionamento ácido e silano (10HF/S/SB: 24,82, 10HF/S/SBM: 24,90) foram superiores $(p<0.001)$ aos grupos tratados com condicionamento ácido apenas (10HF/SB: 16,47,10HF/SBM: 19,94) ou apenas silano (S/SB: 18,42, S/SBM: 13,24). Todos os grupos apresentaram uma predominância de falha adesiva. A silanização deve ser um passo clínico em cimentação de estruturas cerâmicas reforçadas por dissilicato de lítio, mesmo com a aplicação do adesivo universal que contém em sua formulação um silano.

\section{References}

1. Fabião $M M$, Stape $T H$, Yanikian $C R$, de Lima $A F$, Pizi EC, Baron GM, et al.. Influence of different adhesive protocols on ceramic bond strength and degree of conversion of resin cements. Int J Adhes Adhes 2015;62:7-13.

2. Kalavacharla V, Lawson N, Ramp L, Burgess J. Influence of etching protocol and silane treatment with a universal adhesive on lithium disilicate bond strength. Oper Dent 2015;40:372-378.

3. Belli R, Geinzer E, Muschweck A, Petschelt A, Lohbauer U. Mechanical fatigue degradation of ceramics versus resin composites for dental restorations. Dent Mater 2014;30:424-432.

4. Wolfart S, Eschbach S, Scherrer S, Kern M. Clinical outcome of threeunit lithium-disilicate glass-ceramic fixed dental prostheses: up to 8 years results. Dent Mater 2009;25:63-71.

5. Brunot-Gohin C, Duval JL, Azogui EE, Jannetta R, Pezron I, LaurentMaquin D, et al.. Soft tissue adhesion of polished versus glazed lithium disilicate ceramic for dental applications. Dent Mater 2013;29:205212.

6. Guess PC, Zavanelli RA, Silva NR, Bonfante EA, Coelbo PG, Thompson VP. Monolithic CAD/CAM lithium disilicate versus veneered Y-TZP crowns: comparison of failure modes and reliability after fatigue. Int J Prosthodont 2010;23:434-442.

7. Guarda GB, Correr AB, Gonçalves LS, Costa AR, Borges GA, Sinhoreti $M A$, et al.. Effects of surface treatments, thermocycling, and cyclic loading on the bond strength of a resin cement bonded to a lithium disilicate glass ceramic. Oper Dent 2013;38:208-217.

8. Kursoglu P, Motro PF, Yurdaguven H. Shear bond strength of resin cement to an acid etched and a laser irradiated ceramic surface. J Adv Prosthodont 2013;5:98-103.

9. Spohr AM, Correr-Sobrinho L, Consani S, Sinhoreti MAC, Knowles JC. Influence of surface conditions and silane agent on the bond of resin to IPS Empress 2 ceramic. Int J Prosthodont 2003;16:277-282.
10. Shimada Y, Yamaguchi S, Tagami J. Micro-shear bond strength of dualcured resin cement to glass ceramics. Dent Mater 2002;18:380-388.

11. Amaral M, Belli R, Cesar PF, Valandro LF, Petschelt A, Lohbauer U. The potential of novel primers and universal adhesives to bond to zirconia. J Dent 2014;42:90-98.

12. Zogheib LV, Bona AD, Kimpara ET, McCabe JF. Effect of hydrofluoric acid etching duration on the roughness and flexural strength of a lithium disilicate-based glass ceramic. Braz Dent J 2011;22:45-50.

13. Colares RCR, Neri JR, Souza AMB, Pontes KMF, Mendonça JS, Santiago SL. Effect of surface pretreatments on the microtensile bond strength of lithium-disilicate ceramic repaired with composite resin. Braz Dent J 2013;24:349-352.

14. Neis $C A$, Albuquerque NL, Albuquerque I de $S$, Gomes EA, Souza-Filho $C B$, Feitosa VP, et al.. Surface treatments for repair of feldspathic, leucite - and lithium disilicate-reinforced glass ceramics using composite resin. Braz Dent J 2015;26:152-155.

15. Yoshida Y, Nagakane K, Fukuda R, Nakayama Y, Okazaki M, Shintani $\mathrm{H}$, et al.. Comparative study on adhesive performance of functional monomers. J Dent Res 2004;83:454-458.

16. Kim JH, Chae SY, Lee Y, Han GJ, Cho BH. Effects of Multipurpose, Universal Adhesives on Resin Bonding to Zirconia Ceramic. Oper Dent 2015;40:55-62.

17. Shen C, Oh WS, Williams JR. Effect of postsilanization drying on the bond strength of composite to ceramic. J Prosthet Dent 2004;91:453458.

18. Zaghloul H, Elkassas DW, Haridy MF. Effect of incorporation of silane in the bonding agent on the repair potential of machinable esthetic blocks. Eur J Dent 2014;8:44-52.

19. Matinlinna JP, Vallittu PK. Bonding of resin composites to etchable ceramic surfaces - an insight review of the chemical aspects on surface conditioning. J Oral Rehabil 2007;34:622-630.

20. Lung CY, Matinlinna JP. Aspects of silane coupling agents and surface conditioning in dentistry: An overview. Dent Mater 2012;28:467-477.

21. Iriyama NT, Tango RN, Manetta IP, Sinhoreti MA, Sobrinho LC, Saavedra GS. Effect of light-curing method and indirect veneering materials on the Knoop hardness of a resin cement. Braz Oral Res 2009;23:108-112.

22. Uctasli $\mathrm{S}$, Hasanreisoglu $\mathrm{U}$, Wilson HJ. The attenuation of radiation by porcelain and its effect on polymerization of resin cements. J Oral Rehabil 1994;21:565-575.

23. Tanoue N, Koishi Y, Matsumura H, Atsuta M. Curing depth of different shades of a photo-activated prosthetic composite material. J Oral Rehabil 2001;28:618-623. 